\title{
Aspects that should be considered in a possible revision of the Brazilian Guideline Conama Resolution 357/05
}

\begin{abstract}
Guidelines are adopted to assist the processes of environmental monitoring and safeguard aquatic ecosystems. In Brazil, the Conama Resolution 357/05 (CR) is the main guideline ruling, such a normative mechanism is an instrument of the National Water Resources Policy. However, the CR does not consider specific ecological aspects and just imposes generalist standards for all country. We propose a list of the main elements that should be considered in a possible $\mathrm{CR}$ review according to the literature with the intent to assist the decision-makers during the revision process. Aspects involving ecoregions; biotic communities; organic substances; ammonia behavior; permissiveness related to some limnological variables and water class; pesticides; electrical conductivity; temperature; true color; general values from other countries and emergent micropollutants are proposed. $\mathrm{CR}$ is an extremely useful instrument in the Brazilian scenario, however, its revision and incorporation of the mentioned aspects will contribute to the elaboration of intervention measures and monitoring of national aquatic ecosystems.
\end{abstract}

Volume 4 Issue 5 - 2019

\author{
Fabio Leandro da Silva, ${ }^{1,2}$ Erica Zanardo \\ Oliveira-Andreoli, ${ }^{1,2}$ Raphael Machado, ${ }^{1,2}$ \\ Cátia Cristina Teodoro, ${ }^{3}$ Flor Magali Aguiar \\ López, ${ }^{1,4}$ Ângela Terumi Fushita, ${ }^{1,5}$ Marcela \\ Bianchessi da Cunha-Santino, ${ }^{1,2}$ Irineu \\ Bianchini Jr, \\ 'Laboratory of Bioassays and Mathematics Modeling, \\ Department of Hydrobiology, Universidade Federal de São \\ Carlos, Brazil \\ ${ }^{2}$ Post-Graduate Program in Ecology and Natural Resources, \\ Universidade Federal de São Carlos, Brazil \\ ${ }^{3}$ Post-Graduate Program in Sciences of Environmental \\ Engineering, Universidade de São Paulo, Brazil \\ ${ }^{4}$ Laboratory of Analysis and Environmental Planning, \\ Department of Hydrobiology, Universidade Federal de São \\ Carlos, Brazil \\ ${ }^{5}$ Engineering, Modeling and Applied Social Sciences Center, \\ Universidade Federal do ABC, Brazil
}

Correspondence: Laboratory of Bioassays and Mathematics Modeling, Department of Hydrobiology, Universidade Federal de São Carlos, Rodovia Washington Luiz, km 235, CEP: I3565905, São Carlos, SP, Brazil, Email fabioleodasilva@gmail.com

Received:September II, 2019 | Published:September 25, 2019

\section{Introduction}

We are living the Anthropocene and several threats to the Earth's resilience and 'planetary boundaries' rupture can be listed. ${ }^{1}$ Currently, the natural ecosystems suffer several impacts due to anthropic activities development (e.g. urban expansion, agribusiness, industrial sector), a condition that results in a wide range of environmental disorders, as pollutants/contaminants inputs and natural areas conversion. All these facts can be linked to the fast-changing process that the ecosystems have suffered in the bio-physical element due to human pressure. ${ }^{2}$

This scenario results in runoff increase, water retention decrease and substances input into aquatic ecosystems, the last one is the main factor responsible for changes in water bodies and quality loss, ${ }^{3}$ as well as limnological parameters alteration. Thus the use of background values (i.e. values obtained from local areas characterized by non-anthropic interference and present its original cover) to verify the impacts of human interference becomes increasingly difficult, given the context of pristine areas degradation.

In the face of the need to monitor and safeguard aquatic ecosystems, guidelines are adopted. Guidelines can be defined as general concentrations/descriptive statements derived from indicators (physico-chemical variables, biological indicators) or scientific investigations that aim to provide orientation to protect the ecosystems and the human health. ${ }^{4}$ The established criteria contribute to understand watershed's dynamics and avoid adverse effects to biota, ${ }^{5}$ ecosystems and environmental health. Although, the particularities involved with each guideline do not allow comparations among countries because of differences, ${ }^{3}$ as geology attributes and climate conditions.

The Conama Resolution 357/05 was approved by the Brazilian National Council for the Environment in 2005 and replaced the previous guideline (Conama Resolution 20/86). Basically, the normative mechanism classifies the national superficial hydric bodies in five classes (Special Class, Class I, Class II, Class III, and Class IV) considering conditions for wastewater discharge, the water use, and environmental conditions. All those classes (except Class IV) demonstrate variations of the water indicators in Brazil, the Conama Resolution 357/05 (CR) is the main guideline in force, and such a normative mechanism is an instrument of the National Water Resources Policy in relation to general concentrations and water use preponderance. Class IV is the less restrictive and the most permissive to degradation.

Worth to be mentioned that the values adopted by the CR do not consider ecological aspects and just imposes generalist standards, ${ }^{6}$ 
a situation that differs from other countries (e.g. Canada, Europe Union). In addition, Brazillian agribusiness is characterized by the intense use of pesticides and fertilizers, ${ }^{7}$ a scenario that contributes to water ecosystems contamination and pollution.

Considering the need to safeguard natural water ecosystems and comply with internal/international policies, the Brazilian government should adopt measures that favor water quality and guidelines improvement. Herein, we list the main elements that should be considered in a possible $\mathrm{CR}$ review according to the literature, aiming to assist the decision-makers during the revision process.

\section{Aspects that should be considered during the CR revision}

The structure of the $\mathrm{CR}$ is composed of unique values for concentrations and reference discharges, a situation that confers challenges in relation to ecological flows proposition in a determined hydrographic basin. ${ }^{8}$

The first element that deserves attention is the fact that $\mathrm{CR}$ does not consider the different ecoregions in the country as well as the information related to biotic communities, ${ }^{6,9}$ and intrinsic characteristics, such as the high concentrations of $\mathrm{Fe}$ and $\mathrm{Mg}$ in water bodies inserted in Brazilian savannas areas.

Also is important to stress that the CR lacks guiding values for organic substances (carbon, nitrogen Kjeldahl) and does not cover a range of emergent pollutants (e.g. drugs, pesticides, caffeine). Stand out that the anthropic eutrophication contributes to biodiversity loss. ${ }^{10}$ Worth to mention that the CR does not consider the influence of temperature on the behavior of ammonia compounds and some values adopted as reference are similar to those of environmental agencies in other countries. ${ }^{11}$

Another issue to consider is the permissiveness of CR in relation to some limnological indicators, such as nutrient and trace element concentrations. For example, the $\mathrm{Cd}$ values adopted as guidelines do not contribute to aquatic communities protection because of the chronic effects. ${ }^{6}$

The non-establishment of guiding values for the limnological indicators of the hydric bodies classified as class IV water (i.e. destined only for navigation and landscape harmony), and the noninclusion of scientific studies that address the effects of pollutants/ contaminants on the food chain are other controversial points. In this sense, the $\mathrm{CR}$ is permissive to environmental degradation in some aspects (e.g. Class VI). ${ }^{11}$

A series of pesticides routinely used in Brazil confer risks to ecosystems and human health, yet they do not have guiding values set by the CR. ${ }^{12}$ The $\mathrm{CR}$ has several gaps associated with its interpretation and effluent provisions to address the issue; the Conama Resolution 430/11 has been approved. ${ }^{13}$ Industrial effluents are regulated by Conama Resolution 430/11; however, it specifies only a few substances and allows the release of various contaminants (e.g. drugs, caffeine, antioxidants, bisphenol A) into water bodies. ${ }^{14}$ The contaminants can promote adverse effects on biota. ${ }^{15}$

A background value for temperature and establishment of limit values for electrical conductivity are topics not contemplated by the $\mathrm{CR}$, these values could favor environmental monitoring and indicate wastewater input. ${ }^{16}$ The true color assessment is a similar aspect that can contribute to anthropic interference assessment and should be in the content of the $\mathrm{CR}$.

Some general values stipulated by CR (e.g. dissolved oxygen, $\mathrm{pH}$, total phosphorus) is characterized for their permissiveness and not adequate for the Brazillian context because of their inspiration in guidelines from other countries (especially Canada). ${ }^{17}$ So, is necessary to adopt values that represent the Brazilian reality and take as base scientific data.

Besides the potential toxic properties, the emergent micropollutants do not have critic values established by CR. ${ }^{18}$ Considering the large variety of substances that confers risks to biota and human health, values should be defined to avoid these substances input into aquatic systems without previous treatment.

\section{Conclusion}

$\mathrm{CR}$ is an extremely useful instrument in the Brazilian scenario, however, its revision and incorporation of the mentioned aspects will contribute to the elaboration of intervention measures and monitoring of national aquatic ecosystems, in order to allow less interference in their functioning. We also recommend the establishment of restrictive criteria in relation to the Class IV and the incorporation of aspects related to the ecosystems metabolism and structure.

\section{Acknowledgments}

The financial support was provided by the Coordination for the Improvement of Higher Education Personnel (Proc. 1618451/2016 and 1681405/2017), Consejo Nacional de Ciencia y Tecnología (Proc. 382397/2016) and the National Council of Technological and Scientific Development (Proc. 158927/2018-4 and 141217/2018-9).

\section{Funding}

None.

\section{Conflicts of interest}

The authors declared that there no conflicts of interest.

\section{References}

1. Lange A, Barbier EB, Bateman I, et al. Policy design for the Anthropocene. Nature Sustainability; 2019;2:14-21.

2. Priyadarshini P, Abhilash PC. Towards the transformations of social-ecological systems for sustainable development. Tropical Ecology. 2019;60(1):163-165.

3. Poleto $\mathrm{C}$, Merten GH. Elementos traço em sedimentos urbanos e sua avaliação por guidelines. HOLOS Environment. 2008;8(2):100-118.

4. Queensland Government. Water quality guidelines. Department of Environemt and Science; 2019.

5. Fernandes F, Poleto C. Geochemistry in sediment core for zinc and nickel metals and comparison between indexes of environmental references. Journal of Environmental Engineering. 2018;145(3).

6. Silva SC, Mariani CF, Pompêo M. Critical analysis of CONAMA Resolution No. 357 in light of the European Community Water Framework Directive: case study (Guarapiranga Dam - São Paulo, Brazil). In: Pompêo M, Moschini-Carlos V, Nishimura PY, et al. editors. Reservoir and interface ecology. São Paulo: University of São Paulo; 2015;(1):367-375. 
7. Cardoso ASR, Sousa RAD, Reis LC. Agro is tech, pop, is everything: the (un) veiling of this reality. Geosul. 2019;34(71): 836-857.

8. Marques LOA, Taffarello D, Calijuri MC, et al. Phosphorus and thermotolerant coliforms' loads in Brazilian watersheds with limited data: considerations on the integrated analysis of water quality and quantity. Brazilian Journal of Water Resources. 2019;24(3):1-13.

9. Pizella DG, Souza MP. Environmental sustainability analysis of the Brazilian surface freshwater classification system. Eng Sanit Ambient. 2007;12(2):139-148.

10. Firn J, McGree JM, Harvey E, et al. Leaf nutrients, not specific leaf area, are consistent indicators of elevated nutrient inputs. Nature Ecology \& Evolution. 2019;3:400-406.

11. Reis JAT, Mendonca ASF. Technical analysis of the new Brazilian standards for ammonia in effluents and water bodies. Eng Sanit Ambient. 2009; 14(3):353-362.

12. Montagner CC, Vidal C, Acayaba RD, et al. Trace analysis of pesticides and an assessment of their occurrence in surface and drinking waters from State of São Paulo. Anal Methods. 2014;6(17):6668-6677.
13. Miki MK, Silva BS, Silva AL. Metas incertas de efluentes de ETE's. Revista DAE. 2015:37-48.

14. MontagnerCC, VidalC,Acayaba RD. Emerging contaminants in Brazilian aquatic matrices: current scenario and analytical, ecotoxicological and regulatory aspects. Química Nova. 2017;40(9):1094-1110.

15. Reis Filho RW, Barreiro JC, Vieira EM, et al. Pharmaceutical drugs, WWTP, and hydric resources. Ambiente \& Água. 2007;2(3):54-61.

16. Santos NBC, Santos RHG, Silva RF. Application of multivariate analysis and CONAMA resolution 357/2005 for water quality analysis in Pernambuco rivers. Revista Brasileira de Geografia Física. 2018;11(5):1859-1875.

17. Cunha DGF, Lamparelli M, Calijuri MC. CONAMA Resolution 357/2005: Spatial and temporal analysis of nonconformities in rivers and reservoirs of the state of São Paulo according to their frameworks. (20052009). Sanitary and Environmental Engineering. 2013;18(2):159-168.

18. Borges B, Tonin FS, Zamora PGP, et al. Emerging micro-pollutants of pharmaceutical origin in aqueous matrices of Brazil: a systematic review. Journal of the Center for Natural and Exact Sciences. 2015;37(4):725739 . 